\title{
Deoxypodophyllotoxin Content and Antioxidant Activity of Aerial Parts of Anthriscus sylvestris Hoffm.
}

\author{
Stefano Dall'Acqua ${ }^{\mathrm{a}}$, Michela Giorgetti ${ }^{\mathrm{a}}$, Rinaldo Cervellati ${ }^{\mathrm{b}}$, \\ and Gabbriella Innocentia,* \\ a Dipartimento di Scienze Farmaceutiche, Università degli Studi di Padova, via Marzolo 5, \\ 35131 Padova, Italy. Fax: +390498275366. E-mail: gabbriella.innocenti@unipd.it \\ b Dipartimento di Chimica 'G. Ciamician', Università di Bologna, via Selmi 2, 40126, \\ Bologna, Italy \\ * Author for correspondence and reprint requests \\ Z. Naturforsch. 61c, 658-662 (2006); received February 8/April 10, 2006
}

Deoxypodophyllotoxin content of the aerial parts of Anthriscus sylvestris Hoffm. growing at different altitudes was evaluated in comparison to the roots. The lignan accumulation in ground parts was at least double compared to aerial ones.

In addition antioxidant-guided fractionation of the crude methanol extract of aerial parts was performed with the 2,2-diphenyl-1-picrylhydrazyl (DPPH) test. Active fractions contained mainly luteolin-7-O-glucoside and chlorogenic acid. Antioxidant properties of both crude extract and isolated compounds were also investigated with the Briggs-Rauscher (BR) oscillating reaction. A satisfactory agreement between the results obtained with the two methods was observed.

Key words: Anthriscus sylvestris, Deoxypodophyllotoxin Content, Antioxidant Activity

\section{Introduction}

Anthriscus sylvestris Hoffm. (Apiaceae; wild chervil or cow parsley) is a perennial herb that grows in North America, Europe and Asia. Dried roots are used, mixed with other species, as a haematinic or tonic in China. In Japan the roots and young aerial parts are sometimes used as a food (Kozawa et al., 1982). The roots of $A$. sylvestris produce a different range of lignans, next to the three main lignans deoxypodophyllotoxin, yatein, and anhydropodorhizol (Kozawa et al., 1982; Ikeda et al., 1998a, b). Deoxypodophyllotoxin is an interesting compound correlated to podophyllotoxin, a lignan used as the starting compound for the production of the semi-synthetic anticancer drugs etoposide (VP-16-213), a phosphate analogue, ethopophos, and teniposide (VM-26). However, the isolation of podophyllotoxin from the rhizomes of Podophyllum plants is not a very ideal system for large-scale production and the supply becomes increasingly limited due to the intensive collection (Choudhary et al., 1998). For this reason different authors are searching for alternative sources of podophyllotoxin (Van Uden et al., 1997; Koulman et al., 2001). Because of their content of deoxypodophyllotoxin the rhizomes of $A$. sylvestris could become a valuable source for the bio- technological production of podophyllotoxin (Van Uden et al., 1997).

Up to date few data are available about the chemical composition of $A$. sylvestris aerial parts. The aim of this paper is a comparative evaluation of deoxypodophyllotoxin contents in roots and aerial parts of $A$. sylvestris plants growing in northeast Italy. In addition the in vitro antioxidant properties of the aerial parts of $A$. sylvestris were evaluated.

\section{Results and Discussion}

Phytochemical analysis carried out on the aerial parts of $A$. sylvestris led to the isolation and characterization of seven known compounds, deoxypodophyllotoxin (1), nemerosin (2), anthriscinol methyl ether (3), anthriscusin (4), 1-(3'-methoxy4',5'-methylenedioxyphenyl)-1-methoxy-2-propene (5), luteolin-7- $O$-glucoside (6), and chlorogenic acid (7) (Fig. 1). The two last compounds were isolated for the first time from this plant.

The amounts of deoxypodophyllotoxin in plants of $A$. sylvestris growing at different altitudes were evaluated by HPLC. Results are given in Table I. Variation in lignan content between plants of dif- 
<smiles>COc1cc([C@H]2c3cc4c(cc3C[C@H]3COC(=O)[C@H]23)OCO4)cc(OC)c1OC</smiles><smiles>COc1cc(/C=C2/C(=O)OCC2Cc2ccc3c(c2)OCO3)cc(OC)c1OC</smiles>

1<smiles>COC/C=C/c1cc(OC)c2c(c1)OCO2</smiles><smiles>CC=C(COC(=O)/C(C)=C\C)C(=O)OC/C=C/c1cc(OC)c2c(c1)OCO2</smiles><smiles>C=C[C@@H](OC)c1cc(OC)c2c(c1)OCO2</smiles><smiles>O=c1cc(-c2ccc(O)c(O)c2)oc2cc(OC3CCCCC3)cc(O)c12</smiles><smiles>O=C(/C=C/c1ccc(O)c(O)c1)OC1C[C@](O)(C(=O)O)C[C@H](O)[C@H]1O</smiles>

Fig. 1. Compounds isolated from A. sylvestris aerial parts: deoxypodophyllotoxin (1), nemerosin (2), anthriscinol methyl ether (3), anthriscusin (4), 1-(3'-methoxy4',5'-methylenedioxyphenyl)-1-methoxy-2-propene (5), luteolin-7-O-glucoside (6), and chlorogenic acid (7).

Table I. Deoxypodophyllotoxin contents (g/100 g dry weight) in two different populations of $A$. sylvestris specimens.

\begin{tabular}{llc}
\hline Sample $^{\mathrm{a}}$ & Plant part & Content \\
\hline A & Whole plant sample & $0.260 \pm 0.004$ \\
& Aerial parts & $0.130 \pm 0.003$ \\
& Roots & $0.380 \pm 0.005$ \\
$\mathrm{~B}$ & Whole plant sample & $0.560 \pm 0.001$ \\
& Aerial parts & $0.330 \pm 0.001$ \\
& Roots & $0.780 \pm 0.004$ \\
\hline
\end{tabular}

a A, plants collected at $900 \mathrm{~m}$; B, plants collected at $1200 \mathrm{~m}$. ferent locations was observed. The deoxypodophyllotoxin content differed at least twofold between the high and low altitude sites in both aerial parts and roots. Many environmental factors like precipitation, mean temperature, soil, duration of snow cover, and intensity of radiation under clear sky condition have been reported to differ between low and high altitude sites in temperate zones (Körner, 1999). These various factors can have an impact on the secondary metabolite profile in higher plants (Harborne, 1982). A large variation in the contents of lignans in A. sylvestris plants growing at different locations was also described by Koulman et al. (2001).

The deoxypodophyllotoxin content of roots was higher (about 50\%) than that found in the aerial parts of two different populations of $A$. sylvestris.

Although, the aerial parts contained lower deoxypodophyllotoxin amounts compared to the roots, they could be regarded as an alternative and renewable source of this lignan.

The antioxidant activity of the crude methanol extract (MTE) of $A$. sylvestris was evaluated by the 2,2-diphenyl-1-picrylhydrazyl (DPPH) test.

Table II. Antioxidant activity of methanol extract (MTE) and fractions (F1-F7) by DPPH test.

\begin{tabular}{lc}
\hline Sample & $\mathrm{IC}_{50}[\mu \mathrm{g} / \mathrm{ml}]$ \\
\hline MTE & $184 \pm 10$ \\
F1 & $>200$ \\
F2 & $>200$ \\
F3 & $97 \pm 10$ \\
F4 & $29 \pm 10$ \\
F5 & $25 \pm 3$ \\
F6 & $9 \pm 2$ \\
F7 & $15 \pm 3$ \\
\hline
\end{tabular}

Table III. Antioxidant activity of the isolated compounds.

\begin{tabular}{|c|c|c|}
\hline Sample & $\mathrm{DPPH}\left(\mathrm{IC}_{50}\right)^{\mathrm{a}}$ & 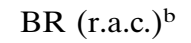 \\
\hline Methanol extract (MTE) & $184 \pm 10$ & $0.046 \pm 0.004$ \\
\hline Deoxypodophyllotoxin & $61.0 \pm 2.4$ & $0.22 \pm 0.02$ \\
\hline Chlorogenic acid & $5.6 \pm 0.1$ & \pm 0.2 \\
\hline Luteolin-7- $O$-glucoside & $15.5 \pm 0.2$ & $0.85 \pm 0.04$ \\
\hline Rutin $^{\mathrm{c}}$ & $5.2 \pm 0.4$ & $0.60 \pm 0.10$ \\
\hline Resorcinol $^{\mathrm{c}}$ & n.d. & 1 \\
\hline
\end{tabular}

a $\mathrm{IC}_{50}$ in $\mu \mathrm{g} / \mathrm{ml}$.

b r.a.c. in $\mu \mathrm{g} / \mathrm{ml}$ for the extract, in $\mu \mathrm{M}$ for pure compounds.

c Rutin and resorcinol were used as reference compounds. 
The crude extract was bioassay-fractionated by a Sephadex column. The $\mathrm{IC}_{50}$ values of the crude extract and the fractions $\mathrm{F} 1 \div \mathrm{F} 7$ are reported in Table II. The highest antioxidant activity was mainly related to $\mathrm{F} 6$.

From this fraction luteolin-7- $O$-glucoside and chlorogenic acid were isolated and identified. The activity of the crude extract and the two isolated compounds was also investigated with both the $\mathrm{DPPH}$ test and the Briggs-Rauscher (BR) method. Results are listed in Table III. As can be seen there is a satisfactory agreement between the results obtained with the two methods.

To better interpret the BR results we report here the relative antioxidant (r.a.c.) value of a methanol extract from Wulfenia carinthiaca Jacq., that is $(0.15 \pm 0.01) \mu \mathrm{g} / \mathrm{ml}$ resorcinol $(\mathrm{Re})$ equivalents: it must be taken into account that the $W$. carinthiaca extract contains the very powerful antioxidants phenylpropanoid glycosides (Cervellati et al., 2004b). Chlorogenic acid is a well-known antioxidant with DNA-protecting properties (Schweiger et al., 2005); its r.a.c. value is indeed high. For comparison the r.a.c. values of rosmarinic acid and cyanidin-3-O- $\beta$-glucopyranoside are $(3.99 \pm 0.08) \mu \mathrm{M} \quad \operatorname{Re}$ equivalents and (1.95 \pm 0.06) $\mu \mathrm{M}$ Re equivalents, respectively (Cervellati $e t$ al., 2002). Luteolin-7-O-glucoside shows a relative antioxidant activity similar to that found for epigallocatechin (0.90) and epicatechingallate (0.80) (Bacchelli, 2004).

\section{Experimental}

\section{Plant material}

The plants of Anthriscus sylvestris Hoffm. growing at two different altitude sites, one at Bivio Pian Rosada at $900 \mathrm{~m}$ (sample A) and the other at Mt. Calvario-Cansiglio at $1200 \mathrm{~m}$ (sample B) (Treviso, Italy), were collected in July 2004. The plants were identified by Prof. E. M. Cappelletti, Botanical Garden of Padova, Padova, Italy, and the voucher specimens were deposited at the Department of Pharmaceutical Sciences, University of Padova, Padova, Italy ( ${ }^{\circ}$ ASPR0704 and ASCC0704).

\section{Chemicals and apparatus}

UV spectra: Perkin-Elmer lambda-25 spectrophotometer; NMR: Bruker AMX-300 spectrometer; HR-MS: Mariner API-TOF mass spectrometer. Podophyllotoxin, DPPH were obtained from Sigma Aldrich; solvents from Carlo Erba were of analytical or HPLC grade. For BR test: Malonic acid (MA, Merck; reagent grade, $>99 \%$ ), manganese(II) sulphate monohydrate (Merck; reagent grade, >99\%), $\mathrm{NaIO}_{3}$, anhydrous $\mathrm{Na}_{2} \mathrm{CO}_{3}$ (Merck; reagent grade, $\geq 99.9 \%$ ) and resorcinol (= benzene-1,3-diol; Fluka; reagent grade, $\geq 98 \%$ ) were used without further purification. $\mathrm{HClO}_{4}$ (Merck; 70-72\% v/v), $\mathrm{H}_{2} \mathrm{O}_{2}$ (Merck; 35\% v/v), and other chemicals were of analytical grade. All stock solutions were prepared from doubly distilled, deionized water. Perchloric acid was analyzed by titration vs. standard $0.1 \mathrm{M} \mathrm{NaOH}$ (Merck). $\mathrm{H}_{2} \mathrm{O}_{2}$ was standardized daily by manganometric analysis. Oscillations in the BR mixtures were followed potentiometrically by recording the potential of the mixture using a coupled bright platinum electrode (Hamilton, model P/N 238 945S7; Crison, Bologna) - reference electrode (double junction $\mathrm{Ag} / \mathrm{AgCl}$; Ingold, model 373-90WTE-ISE-S7; Urdorf, Switzerland). Electrodes were connected to a $\mathrm{pH}$ multimeter (WTW, model pH 540 GLP) controlled by an IBM-compatible PC.

\section{Chemical analysis}

Air-dried and powdered aerial parts of $A$. sylvestris (50 g; sample B) were exhaustively extracted in a Soxhlet apparatus with $\mathrm{MeOH}$. The solvent was removed under vacuum. Yield in weight of residue, referring to the weight of dry material extracted, was $12 \mathrm{~g}$ (MTE). $6 \mathrm{~g}$ of the residue was applied to a Sephadex LH 20 column $(250 \mathrm{ml})$ and eluted with $\mathrm{MeOH}$. Fifty-five fractions were obtained and combined on the basis of their chromatographic behaviour into seven fractions (F1 F7) and tested for their antioxidant activity by the DPPH method (Hatano et al., 1988). Further chromatographic steps on a silica gel column and silica gel plates led to the isolation of deoxypodophyllotoxin (1), nemerosin (2), anthriscinol methyl ether (3), anthriscusin (4), 1-(3'-methoxy-4', 5' -methylenedioxyphenyl)-1-methoxy-2-propene (5), luteolin-7-O-glucoside (6), and chlorogenic acid (7). The structures of compounds $\mathbf{1 - 5}$ were achieved by comparison of their spectral data (UV, HRMS, ${ }^{1} \mathrm{H}$ NMR and ${ }^{13} \mathrm{C}$ NMR) with those reported in the literature for the same compounds (Ikeda et al., 1998a, b). Luteolin-7-O-glucoside (6) and chlorogenic acid (7) were identified on the basis of their UV, NMR and MS spectra by comparison with authentic samples purchased from Roth (Germany) and Sigma-Aldrich Corp., respectively. 
Extraction, isolation and evaluation of deoxyphodophyllotoxin in the plants of $A$. sylvestris

Extraction and isolation of deoxypodophyllotoxin from roots

$35 \mathrm{~g}$ of air-dried and powdered roots (sample B) were exhaustively extracted at room temperature using solvents of increasing polarity, namely petroleum ether, chloroform and methanol.

The solvents were removed under vacuum. The petroleum ether extract was chromatographed on a silica gel column (eluted with cyclohexane/ $\mathrm{MeOH}$ in increasing ratios). Further chromatographic steps on silica gel plates (toluene/acetone, $2: 1 \mathrm{v} / \mathrm{v}$ ) led to the isolation of deoxypodophyllotoxin. The lignan was identified on the basis of its spectral data (UV, HRMS, 1D and 2D NMR) and by comparison with those reported in the literature for the same compound (Ikeda et al., 1998a, b).

Deoxypodophyllotoxin was further purified by HPLC to $98.5 \%$ of purity and used to perform a calibration curve.

\section{Deoxypodophyllotoxin content}

The deoxypodophyllotoxin contents in the different samples were performed by HPLC under the following conditions: Spherisorb C18 $5 \mu \mathrm{m}$ $(250 \times 4.6 \mathrm{~mm}$ I.D. $)$ column; AcCN/ammonium acetate $0.02 \mathrm{M}(\mathrm{pH} 5.00)(60: 40 ; \mathrm{v} / \mathrm{v})$ as mobile phase; $1.0 \mathrm{ml} / \mathrm{min}$ flow rate; $10 \mu \mathrm{l}$ sample was injected; detection at $290 \mathrm{~nm}$. Deoxypodophyllotoxin retention time was $8.86 \mathrm{~min}$.

Quantification of deoxypodophyllotoxin in different samples was carried out using podophyllotoxin (Sigma) as internal standard. A calibration curve was determined using a series of standard solutions containing a constant amount of internal

Bacchelli V. (2004), Attività antiossidante di catechine da the verde e di altre sostanze di origine naturale. Thesis for the degree in Pharmaceutical Chemistry, Università di Bologna, Bologna, Italy, pp. 56-57.

Cervellati R., Renzulli C., Guerra M. C., and Speroni E. (2002), Evaluation of antioxidant activity of some natural polyphenolic compounds using the BriggsRauscher reaction method. J. Agric. Food Chem. 50, $7504-7509$.

Cervellati R., Innocenti G., Dall'Acqua S., Costa S., and Sartini E. (2004a), Polyphenols from Polygala spp. and their antioxidant activity. Chem. Biodiversity 1, 415-425 (and references therein). standard with varying amounts of the stock deoxypodophyllotoxin $(R=0.9998)$. Revelation limit was $5.1 \mu \mathrm{g}$.

150-mg samples of dried roots or aerial parts with addition of internal standard, were extracted exhaustively with $\mathrm{MeOH}$ in ultrasonic cleaning for $5 \mathrm{~min}(3 \times 5 \mathrm{ml})$. The methanol extracts were filtered through a $0.45 \mu \mathrm{m}$ filter. The obtained solutions were analyzed by HPLC. Quoted data are the average values of quantitative determinations performed on two different plant samples. Standard deviation was shown to be less than $5 \%$.

\section{Antioxidant activity}

The crude methanol extract (sample B) and fractions $\mathrm{F} 1 \div \mathrm{F} 7$ were assayed with the $\mathrm{DPPH}$ method as previously described (Hatano et al., 1988). Activities of the crude extract and isolated compounds were also evaluated with the BR method, based on the inhibitory effects by antioxidants, free radical scavengers, and the oscillations of the Briggs-Rauscher oscillating reaction, as previously described (Cervellati et al., 2004a). As a value of antioxidant activity the r.a.c. index was used. This index means the relative activity with respect to concentrations, that is, the ratio [std]/ [smp], where [smp] is the concentration of the sample added to the BR mixture giving a certain inhibition time and [std] is the concentration of the standard (resorcinol) that should give the same inhibition time (Cervellati et al., 2004a).

\section{Acknowledgements}

We thank Prof. E. M. Cappelletti (University of Padova, Italy) for the kind gift of the plants of $A$. sylvestris. The authors are grateful to MIUR for financial support.

Cervellati R., Speroni E., Govoni P., Guerra M. C., Costa S., Arnold U. W., and Stuppner H. (2004b), Wulfenia carinthiaca Jacq., antioxidant and pharmacological activities. Z. Naturforsch. 59c, 255-262.

Choudhary D. K., Kaul B. L., and Khan S. (1998), Cultivation and conservation of Podophyllum hexandrum - An overview. J. Med. Arom. Plant Sci. 20, $1071-1073$.

Harborne G. (1982), Introduction to Ecology Biochemistry. Academic Press, London.

Hatano T., Kagawa H., Yasuhara T., and Okuda T. (1988), Two new flavonoids and other constituents in licorice root: their relative astringency and radical 
scavenging effects. Chem. Pharm. Bull. 36, 20902097.

Ikeda R., Nagao T., Okabe H., Nakano Y., Matsunaga H., Datano M., and Mori M. (1998a), Antiproliferative constituents in Umbelliferae plants. III. Constituents in the root and ground part of Anthriscus sylvestris Hoffm. Chem. Pharm. Bull. 46, 871-874.

Ikeda R., Nagao T., Okabe H., Nakano Y., Matsunaga H., Datano M., and Mori M. (1998b), Antiproliferative constituents in Umbelliferae plants. IV. Constituents in the fruits of Anthriscus sylvestris Hoffm. Chem. Pharm. Bull. 46, 875-878.

Körner C. (1999), Alpine Plant Life. Functional Plant Ecology of High Mountain Ecosystems. Springer, Berlin.

Koulman A., Medarde M., Pras N., and Quax W. J. (2001), A fast and simple GC/MS method for lignan profiling in Anthriscus sylvestris and biosynthetically related plant species. Planta Med. 67, 858-862.
Kozawa M., Baba K., Matsuyama Y., Kido T., Sakai M., and Takemoto T. (1982), Components of the root of Anthriscus sylvestris Hoffm. II. Insecticidal activity. Chem. Pharm. Bull. 30, 2885-2888.

Schweiger S., Cervellati R., Seger C., Ellmerer E. P., About N., Renimel I., Godenir C., André P., Gafner F., and Stuppner H. (2005), Leontopodic acid - a novel highly substituted glucaric acid derivative from Edelweiss (Leontopodium alpinum Cass.) and its antioxidative and DNA protecting properties. Tetrahedron 61, 4621-4630.

Van Uden W., Bos J. A., Boeke G. M., Woerdenbag H. J., and Pras N. (1997), The large scale isolation of deoxypodophyllotoxin from rhizomes of Anthriscus sylvestris followed by its bioconversion into 5-methoxypodophyllotoxin $\beta$-D-glucoside by cell cultures of $\mathrm{Li}$ num flavum. J. Nat. Prod. 60, 401-403. 